\title{
Correction to: Coaching for Managers and Engineers
}

\author{
Carolina Machado and J. Paulo Davim
}

\section{Correction to: \\ C. Machado and J. P. Davim (eds.), Coaching for Managers and Engineers, Management and Industrial Engineering, https://doi.org/10.1007/978-3-030-71105-4}

In the original version of the book, the following belated corrections have been incorporated in Chapters "From Theory to Practice-in Search of Theoretical Approaches Leading to Informed Coaching Practices" and "Coaching for All—New Approaches for Future Challenges" belated corrections has been incorporated as in below:

The affiliation "Instituto Superior Manuel Teixeira Gomes, Universidade Lusófona, Lisbon, Portugal" of author "Carla Gomes da Costa" has been changed to "Instituto Superior Manuel Teixeira Gomes, Lisbon, Portugal". 